\section{Reference intervals for acetylated fetal hemoglobin in healthy newborns}

\author{
Renata Paleari, ${ }^{1}$ Irene Mutta, ${ }^{2}$ \\ Gianluca Musolino, ${ }^{2}$ \\ Alessandro Salvatoni, 2 Massimo Agosti, ${ }^{3}$ \\ Gaia Francescato, ${ }^{3}$ Andrea Mosca ${ }^{1}$ \\ 'Dipartimento di Fisiopatologia Medico- \\ Chirurgica e dei Trapianti, Centro per la \\ Riferibilità Metrologica in Medicina di \\ Laboratorio (CIRME), Università degli \\ Studi di Milano; ${ }^{2}$ Unità Operativa di \\ Endocrinologia, Diabetologia e Pediatria \\ d'Urgenza, Clinica Pediatrica Università \\ degli Studi dell'Insubria, Varese; ${ }^{3}$ Unità \\ Operativa Complessa di Neonatologia e \\ Terapia Intensiva Neonatale, Ospedale \\ F. Del Ponte, Varese, Italy
}

\section{Abstract}

The acetylated fetal hemoglobin (AcHbF) derives from an enzyme-mediated post-translational modification occurring on the N-terminal glycine residues of $\gamma$-chains. At present, no established data are available on reference intervals for AcHbF in newborns. A total of 92 healthy infants, with gestational age between 37 and 41 weeks were selected for the establishment of AcHbF reference intervals. Blood samples were collected by heel pricking, when collecting routine neonatal screening, and the hemoglobin pattern was analyzed by high-performance liquid chromatography. AcHbF results were then normalized for $\mathrm{HbF}$ content in order to account for differences in hemoglobin switch. No difference was found in $\mathrm{AcHbF}$ values between genders $(\mathrm{P}=0.858)$. AcHbF results were as follow: $12.8 \pm 0.8 \%$ (mean \pm standard deviation), reference interval: 11.3-14.3\%. This finding could facilitate further studies aimed to assess the possible use of AcHbF, for instance as a possible fetal metabolic biomarker during pregnancy.

\section{Fetal hemoglobin in healthy newborns}

Fetal hemoglobin (HbF) is the major hemoglobin component at birth, and it is normally replaced by hemoglobin $\mathrm{A}(\mathrm{HbA})$ in the first year of life if no thalassemic syndromes are present. ${ }^{1}$ Some authors indeed believe that the expression of human globin genes reaches the equilibrium after 2 years. ${ }^{2}$

$\mathrm{HbF}$ measurement is clinically useful in the study and diagnosis of some important globin gene disorders where HbF levels may vary considerably (mainly, $\beta$ - and $\delta \beta$-thalassemia, HPHF) and in a number of acquired conditions associate with mild increases of $\mathrm{HbF}^{3}$ Approximately 10-20\% of $\mathrm{HbF}$, either in fetal than in adult blood, is present as a post-translational adduct, under the form of acetylated derivative $(\mathrm{AcHbF})$, produced by the acetylation of the N-terminal glycine residues of the $\gamma$ chains, ${ }^{4,5}$ but there are inconsistent evidences in the literature on how AcHbF may vary during pregnancy. Probably, significant differences in the analytical methodologies employed may explain part of the discrepancies. Indeed, various methods such as ion exchange, affinity chromatography, isoelectric focusing and or spectrophotometry using thiobarbaturic acid and liquid chromatographymass spectrometry have been used so far. ${ }^{6}$ Finally, AcHbF could be potentially used to evaluate possible hypoglycemic episodes in the mother during pregnancy, because glycated hemoglobin in newborn is hardly detectable.

Aim of our work was then to evaluate the reference intervals of $\mathrm{AcHbF}$ in newborns in order to provide a key for the interpretation of possible laboratory findings, not only for healthy newborns, but also with regard to newborns with various pathologies or at risk for various pathologies due to the general conditions of the mother during pregnancy.

A total of 166 newborns (78 males and 88 females, gestational age between 30 and 42 weeks) born at Del Ponte Hospital, Varese, Italy, from October 2011 to July 2012, were recruited. Out of that group, a total of 121 newborns (61 males and 50 females, gestational age between 31 and 42 weeks) were studied, in order to evaluate the relationship between $\mathrm{HbF}, \mathrm{AcHbF}, \mathrm{HbA}$ and gestational age. For the definition of the AcHbF reference interval, a subgroup of 92 healthy infants [ 48 males with gestational age between 37 and 42 weeks (median/IQR: 39.0/1.1 weeks) and 44 females with gestational age between 37 and 42 weeks (median/IQR: 39.3/1.2 weeks)] with adequate birth weight for gestational age was selected. All of them were of Caucasian origin and presented negative neonatal, as well as gestational anamnesis. Newborns of mothers with diabetes, impaired fasting glucose or impaired glucose tolerance (both pre-existing and gestational), as well known carriers of hemoglobinopathies were not included. Five $\mu \mathrm{L}$ blood samples, left out from the routine neonatal screening, were collected between the $2^{\text {nd }}$ and 4 th day of life by heel pricking and stored at $+4^{\circ} \mathrm{C}$ in a dedicated device (HbAlc Capillary Collection System, Bio-Rad Laboratories, Segrate, MI, Italy) until analysis. Hemoglobin pattern was analyzed by high-performance liquid chromatography (Variant II, Dual Kit, BioRad Lab.).
Correspondence: Andrea Mosca, Dipartimento Fisiopatologia Medico-Chirurgica e dei Trapianti, via Fratelli Cervi 93, 20090 Segrate (MI), Italy. Tel. +39.02.5033.0422 - Fax +39.02.9998.7559.

E-mail: andrea.mosca@unimi.it

Key words: fetal hemoglobin, $\mathrm{HbAl}_{c}$, neonatal screening.

Acknowledgments: we thank Dr. Gianni Bertoli (Bio-Rad Laboratories, Segrate, MI, Italy) for having supplied the consumables related to capillary blood sample collection.

Contributions: RP has done all the $\mathrm{Hb}$ measurements, and gave an important contribution to data elaboration; IM, GM have worked on the sample collection and processing at location 1; AS has coordinated the clinical study; MA and GF have worked on the sample collection and processing at location 2; AM has taken care of the manuscript and coordinated the whole work.

Conflict of interests: the authors declare no potential conflict of interests.

Conference presentation: this work was partially presented as poster at the Euromedlab 2013 meeting (www.milan2013.org) in Milano, Italy.

Received for publication: 18 November 2013.

Revision received: 9 May 2014.

Accepted for publication: 9 May 2014.

This work is licensed under a Creative Commons Attribution 3.0 License (by-nc 3.0).

(C) Copyright R. Paleari et al., 2014

Licensee PAGEPress, Italy

Thalassemia Reports 2014; 4:2120

doi:10.4081/thal.2014.2120

A typical separation profile obtained from the analysis of newborn blood is shown in Figure 1. As it can be seen, the AcHbF is eluting at a very early stage of the run, but its separation from the major HbF peak is fairly good.

With regard to the levels of $\mathrm{HbA}, \mathrm{HbF}$ and $\mathrm{AcHbF}$ in relation to gestational age, the data we have obtained are reported in Figure 2 . We have not interpolated the data by any function, but it is clearly evident that the decline in the expression of $\mathrm{HbF}$ is in relation to the progressive increase in $\mathrm{HbA}$, due to the well know switch in the expression of globin genes during the development of the fetus. Overall there is a significant dispersion of the points, but it has already been shown that the switch can be delayed or anticipated in different subjects, in reason of possible polymorphisms or mutations in various genes. ${ }^{7}$

However, if the correlations between these hemoglobins measured at birth are analyzed, what is obtained is reported in Figure 3. This finding proves that, beside the variability in 


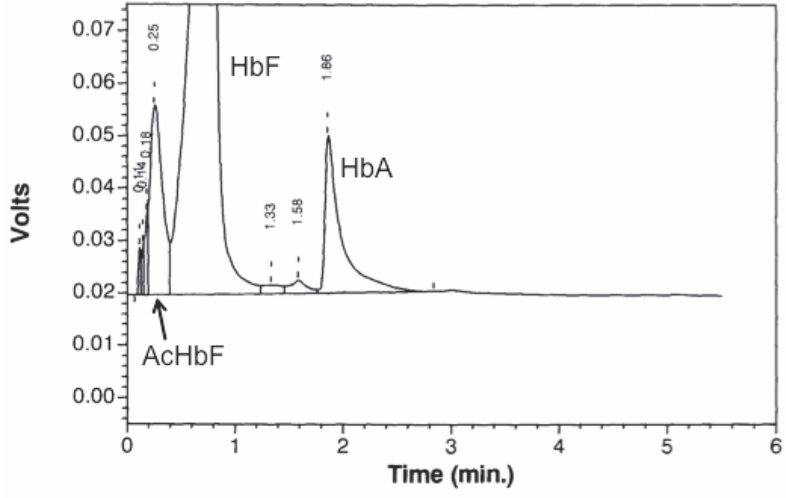

Figure 1. Typical high-performance liquid chromatography profile obtained from the analysis of a blood sample from a newborn.

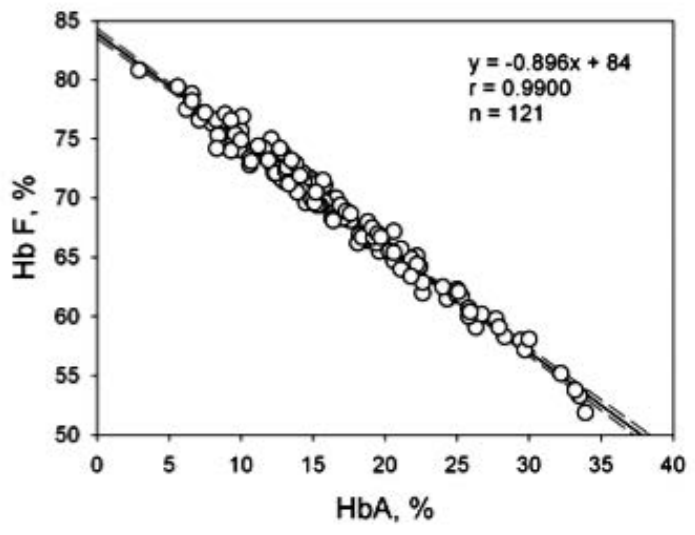

Figure 3. Correlation between fetal hemoglobin $(\mathrm{HbF})$ and $\mathrm{HbA}$ measured at birth.
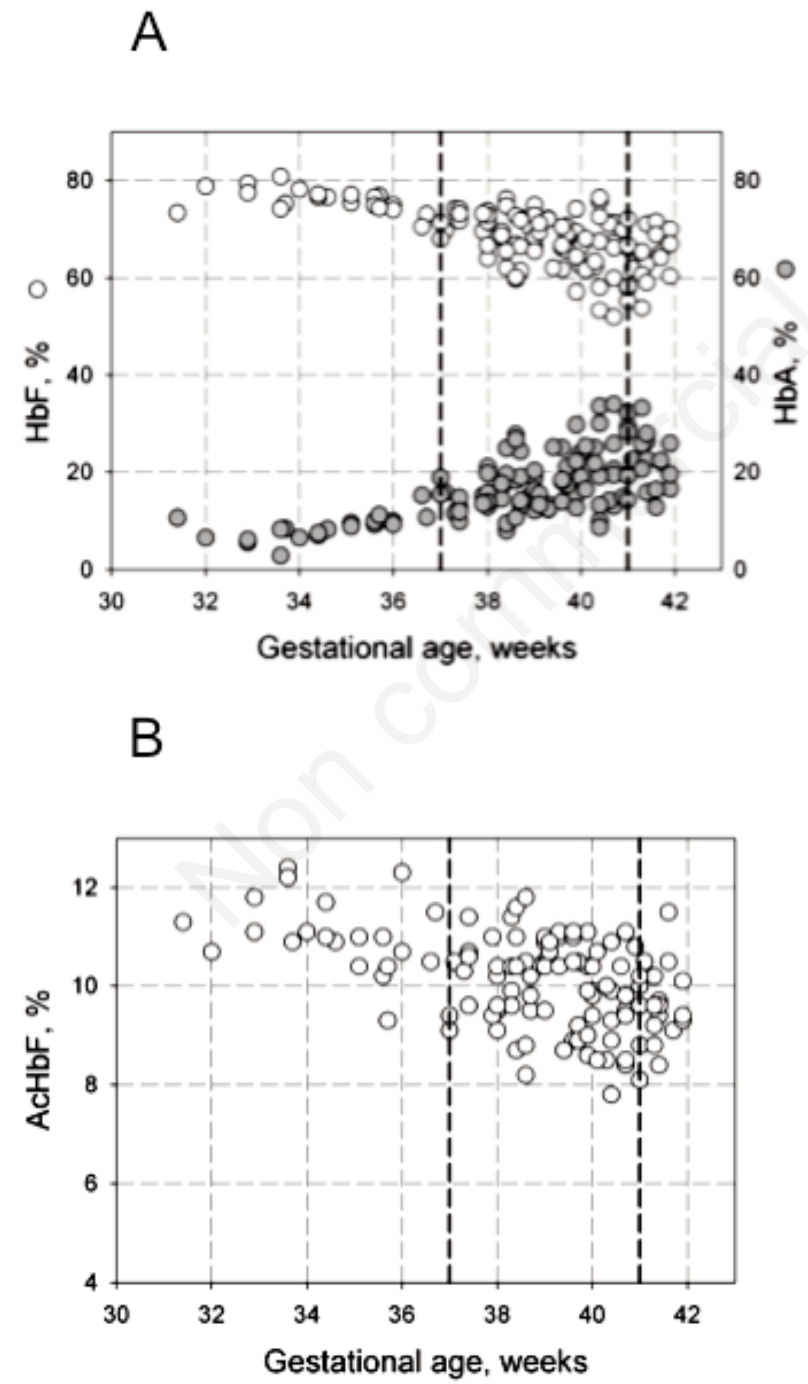

Figure 2. Fetal hemoglobin (HbF), $\mathrm{HbA}(\mathrm{A})$ and acetylated fetal hemoglobin (AcHbF) (B), in relation to gestational age $(n=121)$. The dashed lines mark the physiologic delivery period (i.e. between the $37^{\text {th }}$ to the $41^{\text {st }}$ week of pregnancy). the expression of the globin switch between different subjects as reported in Figure 2, indeed the mechanism of the switch is highly tuned in each subject, as already well known since many years. ${ }^{8}$ For the evaluation of the $\mathrm{AcHbF}$ reference interval, $\mathrm{AcHbF}$ results were normalized for $\mathrm{HbF}$ content in order to account for differences in hemoglobin switch, according to the formula:

$\left[\mathrm{AcHbF}_{\mathrm{adj}}\right]=([\mathrm{AcHbF}] /[\mathrm{AcHbF}]+[\mathrm{HbF}]) \times 100$

No difference was found in $\mathrm{AcHbF}_{\text {adj }}$ values between genders $(\mathrm{P}=0.858)$ and the $\mathrm{AcHbF}_{\text {adj }}$ values were found to have a normal distribution (Shapiro-Wilk test, $\mathrm{P}=0.737$ ). The overall $\mathrm{AcHbF}_{\text {adj }}$ results were: $12.8 \pm 0.8 \%$ (mean \pm standard deviation), and the reference interval (2.5-97.5 centiles) were: $11.3-14.3 \%$. No relevant correlation between $\mathrm{AcHbF}_{\text {adj }}$ and newborn birth weight or length was found.

\section{Conclusions}

In conclusion, the reference intervals for $\mathrm{AcHbF}$ have been defined in a well-characterized population of healthy newborns of not diabetic mothers. This finding could facilitate further studies aimed to assess the possible use of $\mathrm{AcHbF}$ as an index of fetal exposure to glucose during pregnancy.

\section{References}

1. Ohls RK, Christensen RD. Developmental of the hematopoietic system. In: Kliegman RM, Beheman RE, Jenson HB, Santon BF, eds. Nelson textbook of pediatrics. 18 ed. Philadelphia: Saunders Elsevier; 2008. pp 
1997-2003.

2. Birgens H, Ljung R. The thalassemia syndromes. Scan J Clin Lab Invest 2007;67:1126.

3. Mosca A, Paleari R, Leone D, Ivaldi G. The relevance of hemoglobin $\mathrm{F}$ measurement in the diagnosis of thalassemias and related hemoglobinopathies. Clin Biochem 2009;42:1797-801.

4. Garlick RL, Mazer JS, Himelstein AL, et al.
Acetylation of human hemoglobin occurs throughout erythroid cell maturation. Biochim Biophys Acta 1984;799:29-37.

5. Kasten-Jolly J, Abraham EC. Heterogeneity in the globin chain composition of a human minor fetal hemoglobin component. Biochim Biophys Acta 1985;829:6-12.

6. Davison AS, Green BN, Roberts NB. Fetal hemoglobin: assessment of glycation and acetylation status by electrospray ioniza- tion mass spectrometry. Clin Chem Lab Med 2008;46:1230-8.

7. Satta S, Perseu L, Maccioni L, et al. Delayed fetal hemoglobin switching in subjects with KLF1 gene mutation. Blood Cell Mol Dis 2012;48:22-4.

8. Weatherall DJ, Clegg JB. The thalassaemia syndromes. 4th ed. Oxford: Blackwell Scientific Publication; 1981. 